\begin{tabular}{|c|l|}
\hline Title & $\begin{array}{l}\text { Influence of Solution Temperature and Surfactants on Morphologies of Tin Oxide Produced Using a Solution Plasma } \\
\text { Technique }\end{array}$ \\
\hline Author(s) & Saito, Genki; Hosokai, Sou; Tsubota, Masakatsu; A kiyama, Tomohiro \\
\hline Citation & $\begin{array}{l}\text { Crystal Growth \& Design, 12(5), 2455-2459 } \\
\text { https:/doi.org/L0.1021/cg300083k }\end{array}$ \\
\hline Issue Date & 2012-05 \\
\hline Doc URL & http://hdl.handle.net/2115/58413 \\
\hline Type & article (author version) \\
\hline Additional Information & There are other files related to this item in HUSCAP. Check the above URL. \\
\hline File Information & SnO_ver41-2.pdf (本文) \\
\hline
\end{tabular}

Instructions for use 


\title{
Influence of solution temperature and surfactants on morphologies of tin oxide produced using a solution plasma technique
}

\author{
Genki Saito, Sou Hosokai, Masakatsu Tsubota, Tomohiro Akiyama*
}

Center for Advanced Research of Energy and Materials, Hokkaido University,

Sapporo 060-8628, Japan

*E-mail: takiyama@eng.hokudai.ac.jp 


\begin{abstract}
Single-crystalline tin oxide $(\mathrm{SnO})$ plates were synthesized by a solution plasma technique using an Sn wire. In the experiments, we applied a voltage of $400 \mathrm{~V}$ in a $0.001 \mathrm{M} \mathrm{K}_{2} \mathrm{CO}_{3}$ solution. The effects on the products of the solution temperature, the use of surfactants, and the cooling rate were investigated. A solution temperature above 95.0 ${ }^{\circ} \mathrm{C}$ was effective for producing single-crystal $\mathrm{SnO}$ plates. The addition of poly(vinyl alcohol) (PVA) significantly stabilized the $\mathrm{Sn}_{6} \mathrm{O}_{4}(\mathrm{OH})_{4}$ octahedrons. In the case of cetyltrimethylammonium bromide (CTAB) addition, $\mathrm{SnO}$ and $\mathrm{Sn}$ crystals with plate crystal, particle, and rod morphologies were formed. Quenching the solution affected the product size. Faster cooling rates reduced the size of the $\mathrm{SnO}$ plates. $\mathrm{SnO}$ plates with (001) plane faces precipitated from $\mathrm{Sn}(\mathrm{OH})_{3}{ }^{-}$ions to form plate-like crystals as a result of the difference in the growth rates at each plane.
\end{abstract}

\title{
KEYWORDS
}

nanoparticles, crystal growth, plasma discharge, electrolysis, $\mathrm{SnO}$, solution plasma 


\section{Introduction}

Tin oxides such as rutile-type tin dioxide $\left(\mathrm{SnO}_{2}\right)$ and tetragonal tin oxide $(\mathrm{SnO})$ have recently received increasing attention as functional materials. Rutile-type $\mathrm{SnO}_{2}$ is used for various devices such as transparent electrodes ${ }^{1,2}$ and gas sensors ${ }^{3,4}$, because it is an n-type semiconductor with a wide band gap $\left(\mathrm{E}_{\mathrm{g}}=3.62 \mathrm{eV}\right.$ at $\left.300 \mathrm{~K}\right)$. Tetragonal $\mathrm{SnO}$ and $\mathrm{SnO}_{2}$ are expected to be used as an anode material for lithium ion batteries ${ }^{5-10}$. In particular, SnO-layer plates ${ }^{11}$, nanoflowers ${ }^{12}$, and meshed plates ${ }^{13}$ have shown high specific capacities with a good cycle performance for use in lithium ion batteries.

Controlling the morphology of $\mathrm{SnO}$ crystals has gained increasing importance. An easy way to control crystallization is to add surfactants. Many studies have investigated the effects of surfactants such as polyvinyl alcohol (PVA) $)^{4,14}$, sodium dodecylsulfate $(\mathrm{SDS})^{1,3}$, polyvinyl pyrrolidone $(\mathrm{PVP})^{6}$, and cetyltrimethylammonium bromide $(\mathrm{CTAB})^{8,15}$ on the crystal growth of tin oxide crystals in a solution. The time-temperature history of the process also has a strong influence on the morphology of the product ${ }^{16,17}$. 
Recently, we have newly applied a solution plasma technique ${ }^{18-22}$ for synthesizing $\mathrm{SnO}$ nanocrystals. In the solution plasma technique, a cathode made of $\mathrm{Sn}$ wire is used as a raw material for the synthesis of the nanocrystals. In general, a solution plasma technique offers many advantages: (1) simple equipment, (2) no requirement for a gas supply, (3) higher productivity than conventional solution processes, and (4) applicability to continuous production. However, the possible mechanism for the synthesis of tin oxide nanocrystals has still remained unsolved. In addition, controlling method of morphologies and composition of the products is not established.

Therefore, the purpose of this study is to evaluate the experimental conditions including the solution temperature, the use of surfactant and the cooling rate for producing $\mathrm{SnO}$ nanoparticles by the solution plasma technique. We examined the effects of PVA, SDS and CTAB surfactants as additives, in which these surfactants may affect the crystal growth at the interface between solid and liquid. We also investigated the effect of the solution temperature on the morphologies and composition of the crystals. Finally, a possible mechanism for the synthesis of nanocrystals is proposed on the basis of the results. 


\section{Experimental}

As reported previously, ${ }^{18,20-22}$ the experimental setup consisted of two electrodes in a glass cell. The cathode consisted of an $\mathrm{Sn}$ wire of diameter $1.0 \mathrm{~mm}$ and 99.9 mass\% purity (Nilaco, Tokyo, Japan) placed at the center of the glass cell. A glow discharge plasma was generated around the cathode and was maintained by applying a voltage using a direct-current power-supply (ZX800H, Takasago, Tokyo, Japan). A $0.001 \mathrm{M}$ $\mathrm{K}_{2} \mathrm{CO}_{3}$ solution was used as the electrolyte. Before electrolysis, the solution was heated to $80 \pm 3{ }^{\circ} \mathrm{C}$ on a heating plate equipped with a magnetic stirrer. The applied voltage was $400 \mathrm{~V}$, with voltage control, and the electrolysis time was approximately $30 \mathrm{~min}$. The solution was stirred using a magnetic stirrer at a rate of $1200 \mathrm{rpm}$ during electrolysis.

Table 1 shows the experimental conditions. To study the effect of solution temperature on the products, the solution temperatures were controlled in Runs 1-3. In Runs 4,5 , and 6 , the effect of surfactants on the product was investigated by addition of 0.01 mass\% poly(vinyl alcohol) (PVA, average degree of polymerization: 1400$), 0.001$ M SDS, and a small amount of CTAB, respectively. The cooling rates after electrolysis were also varied; the glass cell with the solution containing the products and ions was 
either immediately quenched in ice-water $\left(0{ }^{\circ} \mathrm{C}, 30 \mathrm{~L}\right)$ after the experiments or allowed to cool gradually in air (Run 7).

Table 1. Experimental conditions.

\begin{tabular}{|c|c|c|c|}
\hline Run & Temperature Control & Surfactants & Cooling after Electrolysis \\
\hline 1 & Natural cooling in air & \multirow{3}{*}{ No } & \multirow{6}{*}{ Quenched using ice-water } \\
\hline 2 & Quenched using $25^{\circ} \mathrm{C}$ water & & \\
\hline 3 & Quenched using ice-water & & \\
\hline 4 & \multirow{4}{*}{ Natural cooling in air } & SDS & \\
\hline 5 & & PVA & \\
\hline 6 & & CTAB & \\
\hline 7 & & No & Natural cooling in air \\
\hline
\end{tabular}


3. Results and Discussion

\subsection{Product morphology and phase}

Figure 1 shows the XRD patterns of the products, and Fig. 2 shows the SEM images of the products. Runs 1-7 correspond to the experimental conditions shown in Table 1 . The experimental results are summarized in Table S1 (Supporting Information). The XRD patterns shown in Fig. 1 indicate that the products were $\mathrm{SnO}, \mathrm{Sn}_{6} \mathrm{O}_{4}(\mathrm{OH})_{4}$, and $\mathrm{Sn}$. Interestingly, $\mathrm{SnO}_{2}$ was not formed, although it is more stable. This suggests that the product was formed not from $\mathrm{Sn}^{4+}$ but from $\mathrm{Sn}^{2+}$ ions. Tetragonal $\mathrm{SnO}$ is a thermodynamically metastable phase. The solution plasma sometimes produces a metastable phase as a result of a high cooling rate. The solubility diagram of Sn species in water at $25^{\circ} \mathrm{C}^{23}$ shows that the solubilities of $\mathrm{Sn}(\mathrm{IV})$ and $\mathrm{Sn}$ (II) species change with $\mathrm{pH}$. There is a possibility that the solution plasma technique produces the $\mathrm{SnO}_{2}$ phase by changing the $\mathrm{pH}$. According to the SEM images shown in Fig. 2, oriented crystals were mainly produced under the conditions used for Runs 1, 2, 4, 6, and 7, and these showed strong SnO peaks in the XRD patterns. Detailed observations of these crystals (Fig. 4S, Supporting Information) show that the crystal thicknesses were less than their widths. We therefore called these oriented crystals "plate-like crystals." These results suggest that the plate-like crystals are $\mathrm{SnO}$. 


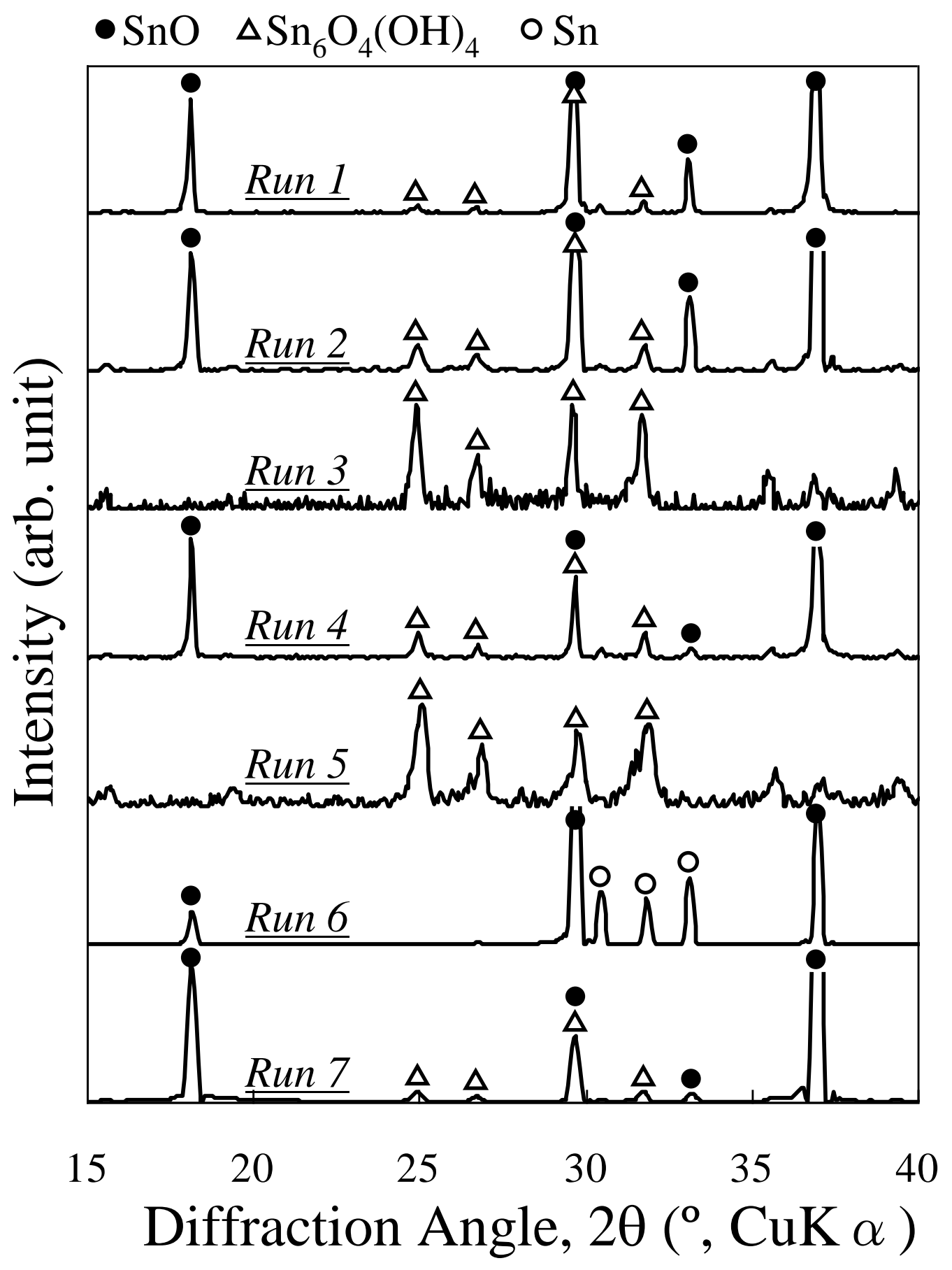

Fig. 1. XRD patterns of products from Runs 1-7 in Table 1. 


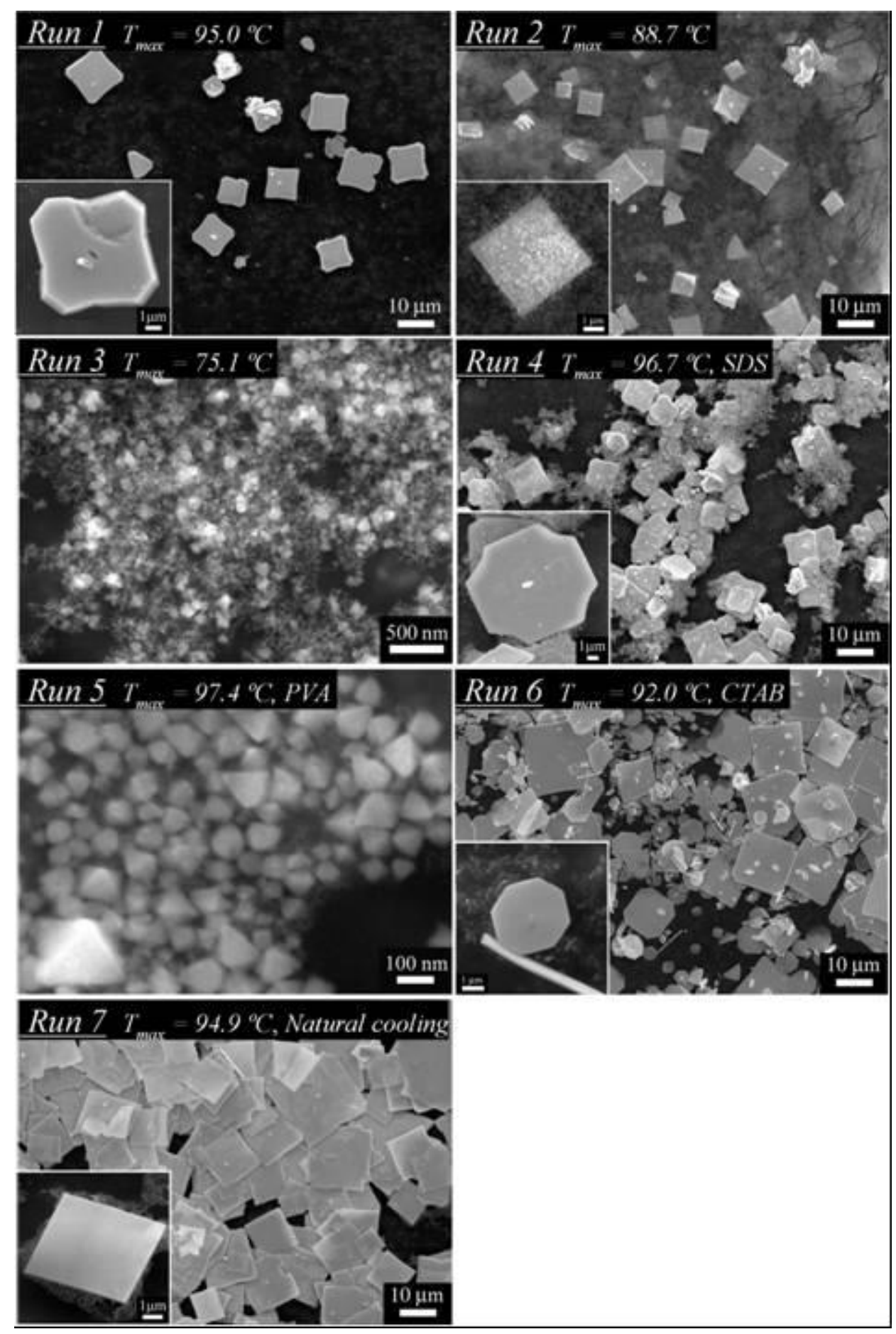

Fig. 2. SEM images of products synthesized under different conditions (Table 1) using $0.001 \mathrm{M} \mathrm{K}_{2} \mathrm{CO}_{3}$ solution as the electrolyte. $T_{\max }$ is the maximum temperature $\left({ }^{\circ} \mathrm{C}\right)$ during electrolysis. 


\subsection{Effect of solution temperature}

In order to control the solution temperatures, the electrolysis solutions were cooled. For Run 3, the electrolysis solution was cooled using ice-water. The electrolysis solution was cooled using water at $25 \pm 5{ }^{\circ} \mathrm{C}$ for Run 2 . In Run 1 , the electrolysis solution was allowed to cool naturally in air. We measured the solution temperatures at certain points. Figure 2 shows SEM images of the products; $T_{\max }$ is the maximum temperature $\left({ }^{\circ} \mathrm{C}\right)$ during electrolysis. Without cooling, the solution temperature increased to $95.0^{\circ} \mathrm{C}$ (Run 1). SnO plates were synthesized under this condition When the electrolysis solution was cooled using ice-water (Run 3), the main phase of the products was $\operatorname{Sn}_{6} \mathrm{O}_{4}(\mathrm{OH})_{4}$ nanoparticles. In the case of cooling using water at $25 \pm 5^{\circ} \mathrm{C}$ (Run 2), both $\mathrm{SnO}$ plates and $\mathrm{Sn}_{6} \mathrm{O}_{4}(\mathrm{OH})_{4}$ nanoparticles precipitated. These results show that the product phase was controlled by the solution temperature. A solution temperature above $95.0{ }^{\circ} \mathrm{C}$ was effective for producing $\mathrm{SnO}$ plates. 


\subsection{Effect of surfactants}

Compared to the case without surfactants (Run 1), the addition of SDS (Run 4) did not affect the morphology and composition of the product. The products produced using SDS were SnO plates, similar to the products produced in Run 1.

When PVA was used as the surfactant (Run 5), $\mathrm{Sn}_{6} \mathrm{O}_{4}(\mathrm{OH})_{4}$ octahedrons were precipitated, in spite of the solution temperature being above $95.0{ }^{\circ} \mathrm{C}$. This is because PVA affected the crystal growth of the product. SDS is an anionic surfactant and has no hydroxyl groups. In contrast, PVA is a crystalline polymer with many hydroxyl groups. Previous papers have reported that the hydroxyl groups in PVA form hydrogen bonds with other hydroxyl groups, ${ }^{14,24}$ as shown in Fig. S1. We speculate that PVA attaches to a specific crystal plane of $\mathrm{Sn}_{6} \mathrm{O}_{4}(\mathrm{OH})_{4}$ as a capping agent, forming octahedrons. PVA probably prevented dehydration of $\mathrm{Sn}_{6} \mathrm{O}_{4}(\mathrm{OH})_{4}$ by forming a coating on the $\mathrm{Sn}_{6} \mathrm{O}_{4}(\mathrm{OH})_{4}$ surface.

In the case of CTAB addition (Run 6), SnO and Sn were formed. The SEM image in Fig. 2 shows that plate crystals, particles, and rods were formed. As described in section 3.5, $\mathrm{SnO}$ and $\mathrm{Sn}_{6} \mathrm{O}_{4}(\mathrm{OH})_{4}$ are probably formed from $\mathrm{Sn}(\mathrm{OH})_{3}{ }^{-}$ions. CTAB is a cationic surfactant, and ionizes completely in water to form $\mathrm{CTA}^{+}$. The $\mathrm{CTA}^{+}$cations form $\mathrm{CTA}^{+}-\mathrm{Sn}(\mathrm{OH})_{3}{ }^{-}$ion pairs by electrostatic interactions. These $\mathrm{CTA}^{+}-\mathrm{Sn}(\mathrm{OH})_{3}{ }^{-}$ion pairs 
are known to be seeds for rod crystal formation. ${ }^{15}$ This is why rods were formed on addition of CTAB. $\mathrm{CTA}^{+}$probably also became attached to the metallic Sn surface to stabilize the metallic particles. 


\subsection{Effect of cooling}

Two methods of cooling the solution after electrolysis were used: natural cooling in air (Run 7) and quenching in ice-water (Run 1). Figure 3 shows the changes in solution temperature for the different cooling methods. When the solution was naturally cooled in air (Run 7), the SnO plates grew larger than those produced when the solution was quenched using ice-water (Run 1). These results indicated that the $\mathrm{Sn}$ ions remained in solution, without precipitation, after electrolysis, and they gradually precipitated as $\mathrm{SnO}$ as the solution temperature decreased. With the slower rate of cooling, the SnO plates grew larger because the rate of crystal growth was higher than the rate of nucleation. The slow cooling rate decreased the number of crystal nuclei, and these nuclei grew large crystals. When the solution was cooled quickly, many crystal nuclei precipitated, and formed small crystals. 


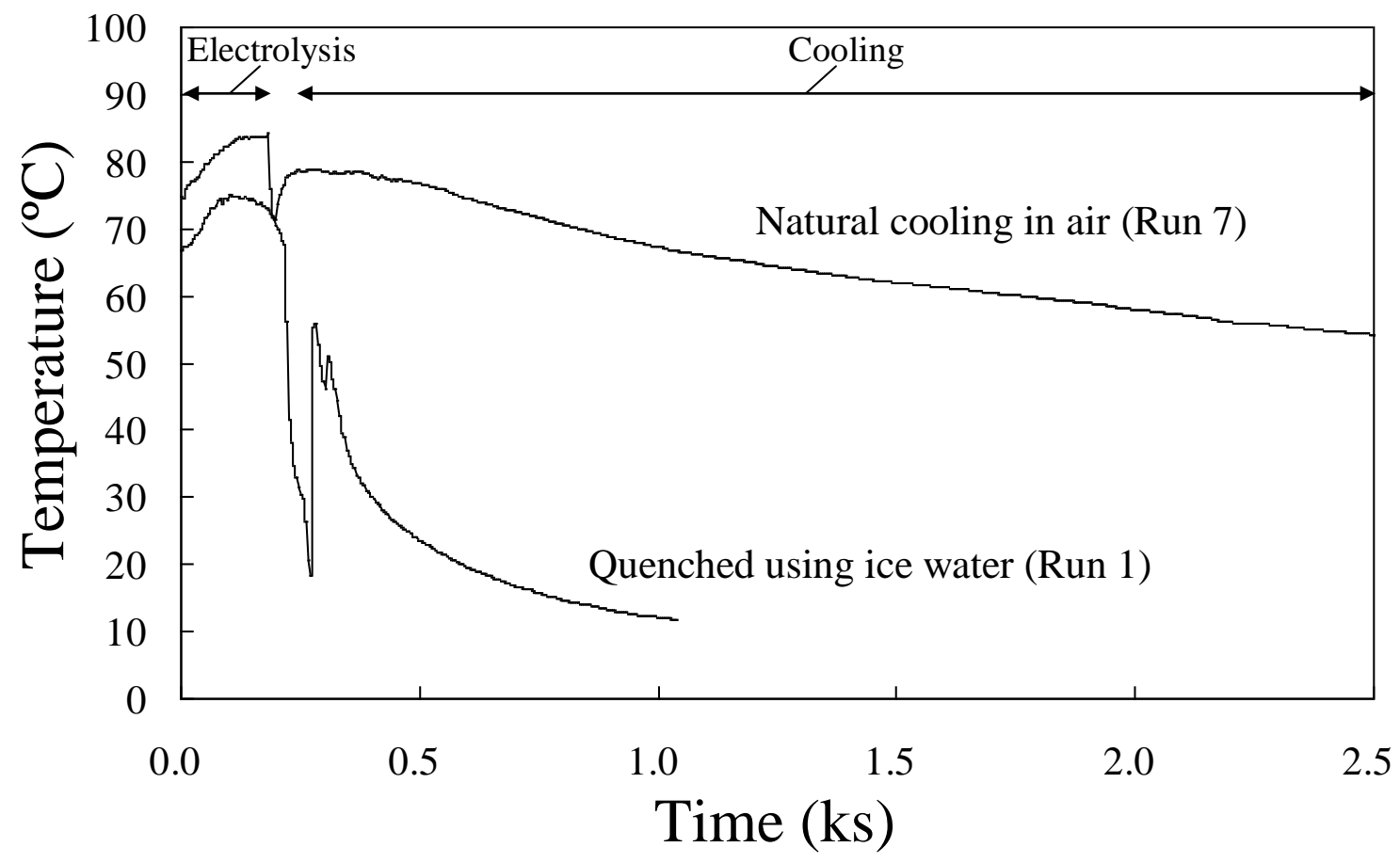

Fig. 3. Changes in solution temperature. The temperature decrease at around $0.2 \mathrm{ks}$ was induced by reconnection of the thermocouple. 


\subsection{Formation mechanism of SnO plate}

We previously reported the preparation of $\mathrm{ZnO}^{22}$ and $\mathrm{CuO}^{20}$ nanocrystals using a solution plasma technique, in which the nanocrystals were precipitated from metal hydroxide ions such as $\mathrm{Zn}(\mathrm{OH})_{4}{ }^{2-}$ and $\mathrm{Cu}(\mathrm{OH})_{4}{ }^{2-}$ using an alkaline solution. Similarly, there is a possibility that, in the present study, the $\mathrm{SnO}$ nanocrystals were formed from $\mathrm{Sn}(\mathrm{OH})_{3}{ }^{-}$ions. $\mathrm{Sn}^{2+}$ ions form $\mathrm{Sn}(\mathrm{OH})_{3}{ }^{-}$ions by the following reaction with hydroxyl ions (equation 1$)$ :

$$
\mathrm{Sn}^{2+}+3(\mathrm{OH})^{-} \rightarrow \mathrm{Sn}(\mathrm{OH})_{3}^{-}
$$

When the solution becomes saturated with $\mathrm{Sn}(\mathrm{OH})_{3}{ }^{-}$ions, precipitation of solid $\mathrm{Sn}_{6} \mathrm{O}_{4}(\mathrm{OH})_{4}$ or $\mathrm{SnO}$ occurs, as shown in equations 2 and 3.

$$
\begin{aligned}
& 6 \mathrm{Sn}(\mathrm{OH})_{3}{ }^{-} \rightarrow \mathrm{Sn}_{6} \mathrm{O}_{4}(\mathrm{OH})_{4}+4 \mathrm{H}_{2} \mathrm{O}+6(\mathrm{OH})^{-} \\
& \mathrm{Sn}(\mathrm{OH})_{3}{ }^{-} \rightarrow \mathrm{SnO}+2 \mathrm{H}_{2} \mathrm{O}+(\mathrm{OH})^{-}
\end{aligned}
$$

When the solution temperature is high, $\mathrm{Sn}(\mathrm{OH})_{3}{ }^{-}$ions tend to form $\mathrm{SnO}$, as in equation (3). At low temperatures, the $\mathrm{Sn}(\mathrm{OH})_{3}{ }^{-}$ions immediately precipitate as $\mathrm{Sn}_{6} \mathrm{O}_{4}(\mathrm{OH})_{4}$ (equation 2) because $\mathrm{Sn}(\mathrm{OH})_{3}{ }^{-}$ions cannot exist as stable ions in solution. 
TEM observations were carried out to investigate the crystal structures of the $\mathrm{SnO}$ plates and $\mathrm{Sn}_{6} \mathrm{O}_{4}(\mathrm{OH})_{4}$ crystals. Figures $4(\mathrm{a}-\mathrm{c})$ show the TEM images of the SnO plates obtained in Run 1. The insets show the corresponding selected area electron diffraction (SAED) patterns. The SAED patterns show that the square plates were single-crystalline tetragonal $\mathrm{SnO}$, with the plate faces on the (001) plane. This crystal structure is consistent with those of other $\mathrm{SnO}$ plates produced by different methods. ${ }^{26}$ However, the sides of the square plates had different planes at each plate. The sides of plate-like crystals (Fig. 4a) were along the (110) plane, and the sides of plates (Fig. 4b) were on the (200) plane. We assumed that the (001) plane of $\mathrm{SnO}$ was the most stable and that the growth rate in the <001> direction was much slower than that in the [110] and $<100>$ directions as a result of the differences in surface energy. The SnO crystals grew to form a plate-like crystal. There have been few reports on the surface energy of $\mathrm{SnO}$ crystals. Generally, in a solution synthesis, oriented crystals are synthesized as a result of the differences in growth rates at each plane. In the case of $\mathrm{ZnO}$, the [0001] surface has a high surface energy and the $<0001>$ direction has a high growth rate. ${ }^{29}$ Similarly, the [001] plane of SnO probably has the lowest surface energy. This is why the $\mathrm{SnO}$ crystals grew to form plate-like crystals. 
SEM and TEM were used to observe a crystal of the intermediate product $\mathrm{Sn}_{6} \mathrm{O}_{4}(\mathrm{OH})_{4}$, which was formed along with the $\mathrm{SnO}$ plates in Run 7. Figures $4(\mathrm{~d}-\mathrm{f})$ show the SEM and TEM images of the $\mathrm{Sn}_{6} \mathrm{O}_{4}(\mathrm{OH})_{4}$ skeleton crystal. The SEM images of the $\mathrm{Sn}_{6} \mathrm{O}_{4}(\mathrm{OH})_{4}$ skeleton crystal in Fig. 4(d) show a square morphology. This skeleton crystal probably grew into an SnO plate. Figure 4(e) shows the TEM image of a skeleton crystal similar to the skeleton crystal shown in Fig. 4(d). The SAED patterns shown in Fig. 4(f) are consistent with the $\mathrm{Sn}_{6} \mathrm{O}_{4}(\mathrm{OH})_{4}$ crystal structure, and the growth direction was along the [110] direction. Subsequently, an octahedron grew in the [110] direction, and new octahedrons attached to the tip of the first octahedron. The octahedrons have rough surfaces with many peaks because many octahedrons agglomerate epitaxially. According to the literature, ${ }^{28} \mathrm{Sn}_{6} \mathrm{O}_{4}(\mathrm{OH})_{4}$ has a tetragonal structure with $a=7.9268 \AA$ and $c=9.1025 \AA$. The growth rate along the $z$-axis is probably different from those along the $x$-axis and the $y$-axis. This difference resulted in growth of the $\mathrm{Sn}_{6} \mathrm{O}_{4}(\mathrm{OH})_{4}$ octahedron to give a plate-like skeleton crystal. 


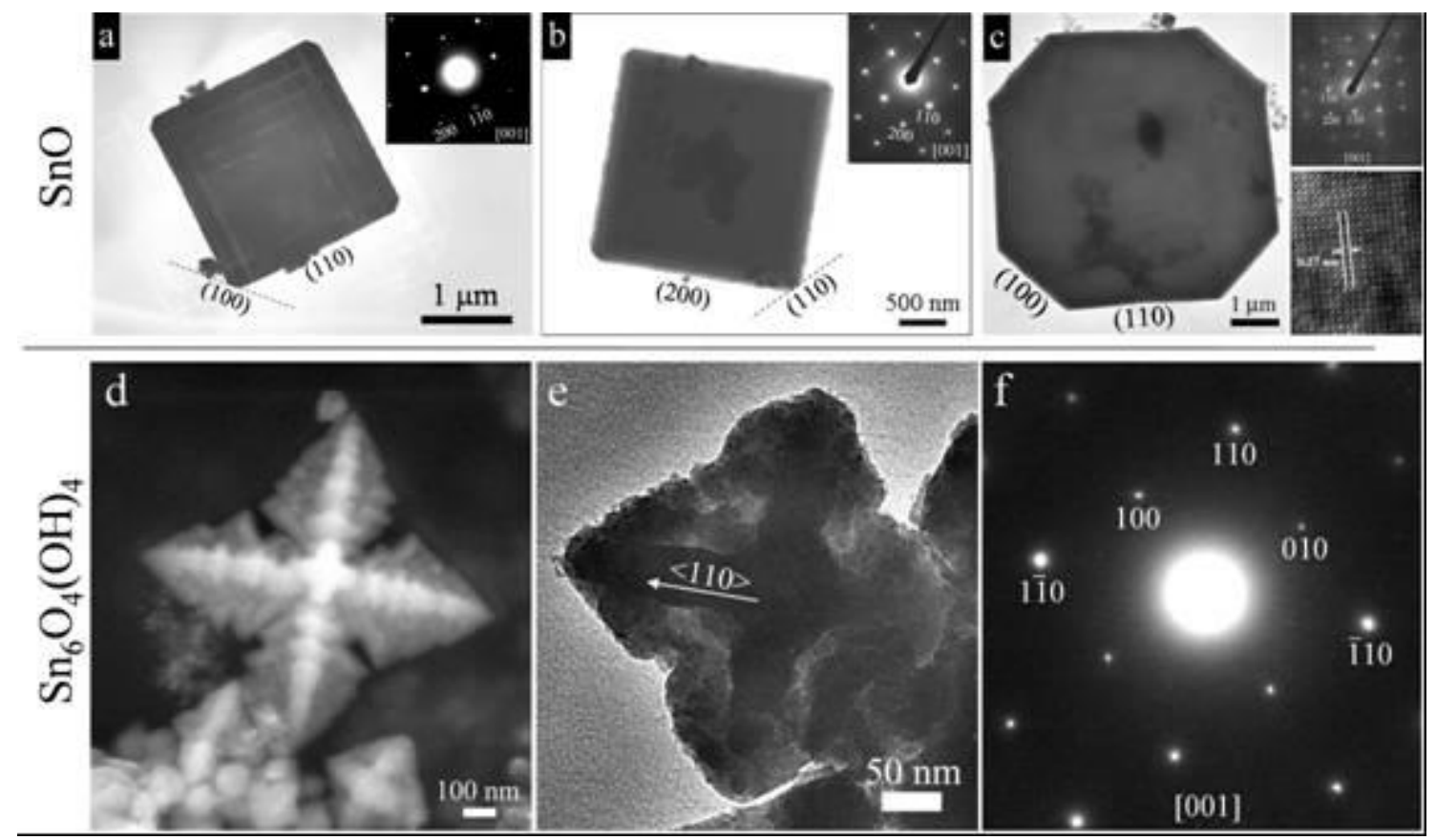

Fig. 4. $(\mathrm{a}-\mathrm{c}) \mathrm{TEM}$ images of the SnO plates. The insets show the SAED patterns of the

$\mathrm{SnO}$ plates recorded with an electron beam parallel to the [001] crystal direction. (d)

SEM images of the $\mathrm{Sn}_{6} \mathrm{O}_{4}(\mathrm{OH})_{4}$ skeleton crystal in the $\mathrm{SnO}$ plates. (e) TEM images of the $\mathrm{Sn}_{6} \mathrm{O}_{4}(\mathrm{OH})_{4}$ skeleton crystal. (f) SAED patterns taken from the $\mathrm{Sn}_{6} \mathrm{O}_{4}(\mathrm{OH})_{4}$ skeleton crystal with the electron beam parallel to the [001] direction. 
IV. Conclusions

In this study, $\mathrm{SnO}$ plates were synthesized by a solution plasma technique using an $\mathrm{Sn}$ wire. In the experiments, we applied a voltage of $400 \mathrm{~V}$ in a $0.001 \mathrm{M} \mathrm{K}_{2} \mathrm{CO}_{3}$ solution. The effects of the solution temperature, the use of surfactants, and the cooling rate on the products were investigated. The following conclusions were derived:

1. At any cooling rate, a solution temperature above $95.0{ }^{\circ} \mathrm{C}$ was effective for producing single-crystal $\mathrm{SnO}$ plates. In contrast, below $75.1^{\circ} \mathrm{C}$, the products were colloidal nanoparticles of $\mathrm{Sn}_{6} \mathrm{O}_{4}(\mathrm{OH})_{4}$.

2. SDS addition did not significantly affect the product. PVA addition significantly stabilized $\mathrm{Sn}_{6} \mathrm{O}_{4}(\mathrm{OH})_{4}$ octahedrons. In the case of CTAB addition, $\mathrm{SnO}$ and $\mathrm{Sn}$ crystals with plate crystal, particle, and rod morphologies were formed.

3. Quenching the solution did not influence the chemical composition of the products; however, it significantly affected the product size. With faster cooling rates, the $\mathrm{SnO}$ plates produced were smaller.

4. SnO plates with (001) plane faces precipitated from $\mathrm{Sn}(\mathrm{OH})_{3}{ }^{-}$ions to form a plate-like crystal as a result of the differences in the growth rates at each plane. 
These results can help us to understand the formation mechanism of tin oxide nanocrystals and of other materials synthesized using solution plasma techniques. The results will also offer many benefits for producing various nanocrystals from precursor using simple equipment without applying pressure or vacuum and production of nanocrystals in easily and quickly. 